\title{
LIDERAZGO EN EL PROCESO DE SUCESIÓN: EL CASO DE UNA EMPRESA FAMILIAR MEXICANA ${ }^{1}$
}

\section{LEADERSHIP IN THE SUCCESSION PROCESS: THE CASE OF A FAMILY BUSINESS FROM MEXICO}

\author{
María Olivia Palafox Soto \\ Instituto Tecnológico de Sonora \\ Depto. de Ciencias Administrativas \\ Cd. Obregón Sonora, México \\ palafoxsotom@gmail.com
}

\author{
Sergio Ochoa Jiménez ${ }^{2}$ \\ Instituto Tecnológico de Sonora \\ Depto. de Ciencias Administrativas \\ Cd. Obregón Sonora, México \\ sochoa@itson.edu.mx
}

\author{
Carlos Armando Jacobo Hernández \\ Instituto Tecnológico de Sonora \\ Depto. de Ciencias Administrativas \\ Cd. Obregón Sonora, México \\ cjacobo@itson.edu.mx
}

Fecha de recepción: 02/04/2019- Fecha de aprobación: 31/05/2019

\section{RESUMEN}

Las empresas familiares son de gran importancia pues han sido generadoras de nuevos empleos a través de los años, permitiéndoles ser objeto de estudio en diversas investigaciones; a pesar de ello, no se ha enfatizado en estudios de caso donde resalten al mismo tiempo el liderazgo y el proceso decisivo en este tipo de organizaciones, conocido como la sucesión. Por lo anterior, se generó la inquietud de estudiar a una empresa que haya pasado por dicho proceso, en donde la principal finalidad es mostrar la capacidad que tiene para resolver problemas, retos y cómo sobrellevar la sucesión, además de conocer si el liderazgo es un factor clave en ello, profundizándolo en mayor medida en un estudio de caso, con guías de entrevista semiestructuradas. Después de analizar e interpretar lo que los informantes mencionan, se obtuvo como resultado que el liderazgo fue pieza fundamental en dicho proceso, con un liderazgo autocrático que fue ejercido por la fundadora de la empresa. En la actualidad, el nuevo dueño ha utilizado diversos tipos de liderazgos cambiantes dependiendo de la situación, Ilamado

\footnotetext{
${ }^{1}$ Publicación financiada con recursos del Programa Fortalecimiento de la Calidad Educativa (PFCE-2018) de la Secretaría de Educación Pública (SEP) de México.

2 Autor de Correspondencia.

“Visión de Futuro" Año 16, Volumen No 23 N², Julio - Diciembre 2019 - Pág. 73 - 89

URL de la Revista: http://visiondefuturo.fce.unam.edu.ar/index.php/visiondefuturo/index

URL del Documento: http://visiondefuturo.fce.unam.edu.ar/index.php/visiondefuturo/issue/view/

ISSN 1668 - 8708 - Versión en Línea

E-mail: revistacientifica@fce.unam.edu.ar

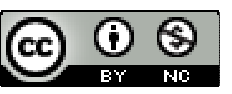

Los trabajos publicados en esta revista están bajo

la licencia Creative

Commons Atribución-

NoComercial 2.5 Arqentina 
situacional. Se recomienda continuar con ese estilo de liderazgo que lo caracteriza y seguir teniendo éxito como una empresa familiar reconocida.

PALABRAS CLAVE: Liderazgo; Sucesión; Familia; Empresa.

\begin{abstract}
The family businesses are of great importance because they have been generators new jobs over the years, it's importance has allowed it to be studied by many investigators, however, and despite there are investigations about family businesses, it hasn't been emphasized in case studies highlighting at the same time the leadership and the decisive process in these business, known as succession process; Therefore, it's worth mentioning the concern to study a well-known company that has gone through this process, where the main purpose is to show the ability to solve problems or challenges and how to cope with the succession process, in addition to knowing if the leadership is a key factor in this, deepening it to a greater extent in a case study, through semi-structured interview guides. After analyzing and interpreting what the informants mention, it was obtained that the leadership was a fundamental piece in this process, ending with an autocratic leadership used by the founder of the company, however, the new owner has changed that using different types of changing leadership depending on the situation, called situational leadership and the main thing to recommend is to continue with that style of leadership that characterizes him and continue like a well-known successful a family business.
\end{abstract}

KEY WORDS: Leadership; Succession; Family, Business.

\title{
INTRODUCCIÓN
}

Las empresas familiares (De aquí en adelante EF), han constituido la forma de organización más antigua que existe, además son el tipo de organización con mayor presencia alrededor del mundo, debido a la importante relación que tienen con la economía y la sociedad (Velázquez et al, 2011), por lo anterior, existe una evidente tendencia en contar un mayor número de este tipo de empresas (Quijada y Ávila, 2016).

Uno de los principales procesos de ellas, es la sucesión, un momento crucial que según Araya (2012) es inevitable para su futuro; ya que se caracteriza por buscar la permanencia de generación en generación; al decidir quién será el sucesor al frente de la misma (San Martin y

\footnotetext{
"Visión de Futuro" Año 16, Volumen N² 23 N², Julio - Diciembre 2019 - Pág. 73 - 89

URL de la Revista: http://visiondefuturo.fce.unam.edu.ar/index.php/visiondefuturo/index

URL del Documento: http://visiondefuturo.fce.unam.edu.ar/index.php/visiondefuturo/issue/view/16

ISSN 1668 - 8708 - Versión en Línea

E-mail: revistacientifica@fce.unam.edu.ar
} 
Durán, 2016), sin lugar a dudas, el proceso más relevante en cualquier tipo de empresa (Tapiés, 2010). Para que esto se realice con éxito, es importante ejercer un tipo de liderazgo que tenga la cualidad esencial de hacer que las cosas funcionen promoviendo el ejemplo y llevando a la organización a lograr lo que se proponga (Gonzalo, 2006).

Diversas investigaciones demuestran que el liderazgo es uno de los elementos más analizados en las EF, debido al gran compromiso, tiempo y esfuerzo realizado por los colaboradores de la misma (Vallejo, 2007); lo cual permite lograr el progreso, conocimiento y motivación para resolver cualquier situación que se presente, de manera particular, con confianza, seguridad y estabilidad para culminar la sucesión (Lozano y Urbano, 2017). Esto permitirá conseguir una mejor planificación a futuro, permitiéndoles subsistir dentro del mercado competitivo (Virick \& Greer, 2012).

Por la importancia que tiene el liderazgo dentro del proceso de sucesión, al grado de definir la supervivencia y continuidad de las EF y ante el desconocimiento de ello en las organizaciones, el presente estudio tiene como finalidad identificar el tipo de liderazgo ejercido durante el proceso de sucesión en una empresa familiar del norte de México y con ello generar propuestas o modelos de mejora que ayuden a ella u otras en su permanencia. El realizar este tipo de investigaciones ayuda a las EF a identificar el tipo de liderazgo ejercido y determinar cuál es el estilo más conveniente que ayude a orientar a la empresa por el camino correcto durante el proceso de sucesión, ya que un liderazgo que es efectivo, ayuda a alcanzar las metas y objetivos establecidos (Ulloa et al, 2012).

Con el fin de cumplir el objetivo de investigación, se realizó una búsqueda documental que se integró en el estado del arte, lo cual conforma la primera parte de este documento. La segunda sección se compone por el método, describiendo a detalle la forma en que se realizaron las entrevistas a los miembros de la empresa en estudio. Posteriormente se describen los resultados enfocados principalmente al tipo de liderazgo y otros factores relacionados con el proceso de sucesión. Finalmente, se incluyen de forma breve las principales conclusiones derivadas de este trabajo.

\section{DESARROLLO}

Las EF son sistemas conformados por ciertos aspectos similares que los unen, como sus relaciones, sus conflictos, su cultura organizacional, filosofía empresarial, entre otras variables (Sandoval y Guerrero, 2010). Además, es importante tener en cuenta algunos factores de este tipo de empresas, como la participación de la familia, donde su primordial logro es el de la "Visión de Futuro" Año 16, Volumen N² 23 N², Julio - Diciembre 2019 - Pág. 73 - 89

URL de la Revista: http://visiondefuturo.fce.unam.edu.ar/index.php/visiondefuturo/index

URL del Documento: http://visiondefuturo.fce.unam.edu.ar/index.php/visiondefuturo/issue/view/16

ISSN 1668 - 8708 - Versión en Línea 
continuidad y que su toma de decisiones sea llevada a cabo por miembros del mismo núcleo familiar. Así pues, diversos autores concuerdan en que una EF está relacionada por los lazos familiares que se tengan dentro de ella, y donde la propiedad de la organización pertenece a la misma familia (Manzano y Ayala, 2002); buscando ofrecer lo esencial a cada trabajador y lograr en ellos un desarrollo profesional y personal, ya sea en lo ético y afectivo, que logre beneficiar a la organización en todos los aspectos, (Salazar, 2014).

La EF es aquella en donde sus miembros pertenecen a un mismo núcleo o sistema familiar compartiendo la empresa y la propiedad en conjunto, con el fin de lograr los objetivos propuestos, permitiendo siempre la continuidad de la misma y manteniendo relación entre los elementos de empresa, propiedad y familia (Tagiuri y Davis, 2012). Por lo que sobrevivir a la planificación de la sucesión mediante estos tres elementos o sistemas es un gran reto para ellas (Arenas y Rico, 2014). En ella se establecen un conjunto de relaciones entre los mismos empleados, principalmente por la asociación familiar dentro de ella, que en muchas situaciones eso podría ocasionar ciertos conflictos, pero a la vez también beneficios (Ochoa et al, 2015).

Desde tiempo atrás, las EF han representado la base de la organización y de la economía, hoy en día son conocidas como el antecedente directo de las grandes y modernas empresas de la actualidad, persiguiendo siempre la sucesión y permanencia, aplicando valores para alcanzar el éxito (Rendón, 2010), y lo que les permite hacerlo es la antigüedad que tienen en el mercado, las generaciones por las que han pasado, el contexto en el que se encuentran (urbano, rural, moderno o tradicional) y la historia que engloba la empresa, pues son características que les han permitido conocer a fondo a la familia desde su pasado hasta su actualidad, y así lograr mantenerse competentes (Jiménez y Piña, 2011).

Todos los elementos de las EF son necesarios para conocer a fondo lo que una empresa de este tipo implica y saber qué rol o función se encuentran desarrollando los colaboradores dentro de la misma. Cabe mencionar que se destacan por mantener ciertas características, como el trabajar con el mismo ritmo que sus antecesores, manteniendo lo que ellos les transmitieron, como conocimientos, valores y habilidades que les enseñaron para que continuaran desarrollándose eficazmente en la empresa (Lee, 2012).

\section{Liderazgo}

El liderazgo se puede definir como una cualidad que debe de tener un alto mando, asegurándose de promover el ejemplo y procurar que los demás actúen motivados para promover la trascendencia de la organización, mejorando el compromiso con la empresa y permitiendo la perdurabilidad de las mismas (Gonzalo, 2006), siendo un buen ejemplo a seguir y logrando influir

\footnotetext{
“Visión de Futuro" Año 16, Volumen N²3 N², Julio - Diciembre 2019 - Pág. 73 - 89

URL de la Revista: http://visiondefuturo.fce.unam.edu.ar/index.php/visiondefuturo/index

URL del Documento: http://visiondefuturo.fce.unam.edu.ar/index.php/visiondefuturo/issue/view/16

ISSN 1668 - 8708 - Versión en Línea

E-mail: revistacientifica@fce.unam.edu.ar
} 
en los demás de diferentes maneras, es de gran importancia en todo tipo de organización, ya que un buen liderazgo contribuye a una buena orientación hacia los objetivos establecidos de la empresa, por lo contrario, el no tener un buen el liderazgo, la empresa puede verse afectada al momento de cumplir sus objetivos y la guía, además, de no poder lograr salir adelante con el proceso de sucesión por el que esté pasando (Van y Yukl, 2015).

Varios autores tienen diversas opiniones sobre el liderazgo, sin embargo, se debe entender que un líder debe ser capaz de poder controlar sus emociones, inteligencia, capacidades y habilidades para traer el bien a la organización, pues los comportamientos y características que mantienen influyen en el actuar de sus subordinados (Zarate y Matviuk, 2012), ya que debe ejercer una influencia positiva en las demás personas, caracterizándose por ser realista, hábil, atrevido, de mente abierta, cercano, innovador, creativo, ético, entre otros aspectos que lo hacen ser un ejemplo para los demás (Carrión, 2017), sobre todo por estar motivado, ejerciendo poder y autoridad ante todos, además de fomentar el cambio, el trabajo en equipo, el rendimiento de los trabajadores y así lograr una satisfacción por el logro obtenido, creando un clima laboral óptimo y armónico (Arteaga y Soraya, 2009).

Se afirma por alguno autores que hay varios tipos de liderazgo, no obstante, otros mencionan que liderazgo solo hay uno, y son los líderes quienes optan distintas maneras de trabajar manteniendo el ejemplo para los demás, también se puede decir que son solo tres formas en las que se puede ejercer el liderazgo, el primero de ellos es el carismático, en donde hace que todos trabajen de una manera armónica y con entusiasmo, también, el tradicional en donde el líder se considera así por naturaleza y por el cargo que tiene, y por último el legítimo quien siempre sigue las normas y procedimientos para que sus subordinados realicen las cosas de la misma manera (Figueroa, 2012), por lo que el éxito de un organización depende en la modo en como ejerzan su liderazgo (Goleman, 2013).

Ampliando el horizontes de los tipos, se puede mencionar que puede hablarse de tipo empresarial el cual es el que influye y dirige en el comportamiento de los trabajadores, el autocrático aquel en el que el líder solo da órdenes, el democrático en donde el líder toma las decisiones en conjunto con sus subordinados con la finalidad de crear un mejor ambiente laboral, (Soto, 2012), existe también el laissez faire que su significado proviene del francés, y quiere decir Dejar hacer en donde el líder es liberal, este tipo de liderazgo en ciertas ocasiones es muy efectivo ya que a veces se debe dejar hacer a los demás las actividades sin estar al pendiente de ellos, también el paternalista, en el que el líder ofrece incentivos o recompensas a quien realice de manera correcta su trabajo, el carismático, en donde el líder es visionario e inspirador lo que hace dar a la empresa una imagen positiva, así como el liderazgo situacional que su efectividad está "Visión de Futuro" Año 16, Volumen N²3 N², Julio - Diciembre 2019 - Pág. 73 - 89

URL de la Revista: http://visiondefuturo.fce.unam.edu.ar/index.php/visiondefuturo/index

URL del Documento: http://visiondefuturo.fce.unam.edu.ar/index.php/visiondefuturo/issue/view/16

ISSN 1668 - 8708 - Versión en Línea 
en la capacidad que tiene el líder o los líderes para responder de diferentes maneras ante diversas situaciones o dificultades (Sánchez, 2000).

Por otra parte, Blake y Mouton (1980) establecieron otros tipos de liderazgo basándose en un modelo denominado Grid gerencial, que consiste en situar la preocupación de los líderes en relación a como se sientan, para darse cuenta de que este modelo es una herramienta que puede ayudar a situar los tipos de liderazgo que son ejercidos en las organizaciones, dando por resultado bastantes estilos que son empleados en las EF y en las que no lo son.

El tema de liderazgo y las EF ha sido abordado con diferentes puntos de vista, tales como el conocer el estilo de liderazgo ejercido por los altos directivos en las EF (Gonzalo, 2006), analizando un tipo de liderazgo en una EF y los efectos que tiene (Vallejo, 2007; Vallejo, 2009) así como, el conocer el liderazgo en las pequeñas empresas de carácter familiar (Bastar, 2006).

\section{Sucesión}

La sucesión es un tema de gran importancia dentro de las empresas, debido a que consiste en lograr la permanencia de la organización, al buscar entre los miembros de la familia quién asumirá el cargo de responsable, una cuestión compleja, ya que existe la incertidumbre del desempeño del sucesor (Araya, 2012). Se distingue por el cambio de poderes, en donde existe la influencia de los fundadores de la empresa, llegando a convertirse en un aspecto ineludible que en algún momento se tiene que llevar a cabo, pues de ello depende el futuro de la misma.

Cabe mencionar, que existen una serie de factores o elementos en el proceso sucesor que lo favorecen y que facilitan su ejecución; entre los cuales se puede mencionar la buena relación, la actitud en la familia, la disposición, el respeto, libertad y autonomía, (Araya, 2012), así como la visión del futuro, las edades que se tengan de los familiares en la empresa, ya que son dos elementos de los cuales el fundador de la empresa toma en cuenta para poder transferir la empresa a otra generación, (González y Navas, 2017), también la armonía familiar que se tenga dentro de la organización y fuera de ella, la confianza entre los empleados con los altos mandos y entre ellos mismos, y sobre todo las relaciones existentes entre el dueño y el sucesor (Mariscal et al, 2016).

Así pues, estudiar la sucesión es un tema de gran importancia, debido a los múltiples autores que se han adentrado a investigar un poco y tomarla como objeto de estudio desde diferentes puntos de vista (Andrade, 2002; Manzano y Ayala, 2002; Santamaría y Pico, 2015; Pantoja et al, 2016).

\section{Análisis del liderazgo en el proceso de sucesión}

\footnotetext{
"Visión de Futuro" Año 16, Volumen N² 23 N², Julio - Diciembre 2019 - Pág. 73 - 89

URL de la Revista: http://visiondefuturo.fce.unam.edu.ar/index.php/visiondefuturo/index

URL del Documento: http://visiondefuturo.fce.unam.edu.ar/index.php/visiondefuturo/issue/view/16

ISSN 1668 - 8708 - Versión en Línea

E-mail: revistacientifica@fce.unam.edu.ar
} 
Lograr mantener un buen liderazgo ante cualquier dificultad es de gran ayuda, ya que se resuelven circunstancias que pueden ser negativas para la empresa, por lo que es preciso aprender a desarrollar todas las virtudes y fortalezas necesarias. Además tiene una repercusión aún más grande durante el proceso de sucesión, pues la EF entra en un estado crítico cuando el liderazgo no se ve presente en este proceso, ya que no garantiza la permanencia y el crecimiento (Saldaña et al, 2016), por lo que contar con ello, resulta ser una ventaja competitiva fundamental, pues permite actuar ante las circunstancias que se puedan presentar de manera imprevista o no, tal como el proceso de sucesión donde el mismo dueño puede guiar a sus trabajadores siendo un buen líder (Gil et al, 2011). A pesar de que el proceso de sucesión es conocido como una adversidad para unos empresarios, para otros es una oportunidad que tienen de poder dejar en manos de otras personas el futuro de la empresa, esperando que sea el más provechoso posible para futuras generaciones.

\section{Metodología}

La presente investigación tiene un alcance descriptivo; ya que busca principalmente especificar lo importante del problema que se está tratando (Cazau, 2006). Así mismo, de carácter cualitativo, lo cual requirió trabajo y análisis a profundidad por ser un caso de estudio, en el cual se examinaron las variables, así como cualidades y características de una organización (Ávila, 2006).

La parte inicial del estudio consistió en la búsqueda documental de artículos científicos relacionados con las variables de estudio, tanto teóricos como empíricos. Posteriormente se analizaron los artículos encontrados, seleccionando solo aquellos que anexaban un instrumento, (guía de entrevista o cuestionario) que se tomarían como base para diseñar una guía de entrevista definitiva. Se obtuvieron un total de 33 artículos, eligiendo dos instrumentos relacionados a estudios similares de sucesión y liderazgo dentro de EF, de los autores Rodríguez y Camacho (2010) y Manning (2013). Se elaboró la guía de preguntas con base en los anteriores artículos, tal como se muestra en la Tabla $N^{\circ} 1$.

\footnotetext{
“Visión de Futuro" Año 16, Volumen N²3 N², Julio - Diciembre 2019 - Pág. 73 - 89

URL de la Revista: http://visiondefuturo.fce.unam.edu.ar/index.php/visiondefuturo/index

URL del Documento: http://visiondefuturo.fce.unam.edu.ar/index.php/visiondefuturo/issue/view/16

ISSN 1668 - 8708 - Versión en Línea 
Tabla $N^{\circ} 1$. Guía de entrevista

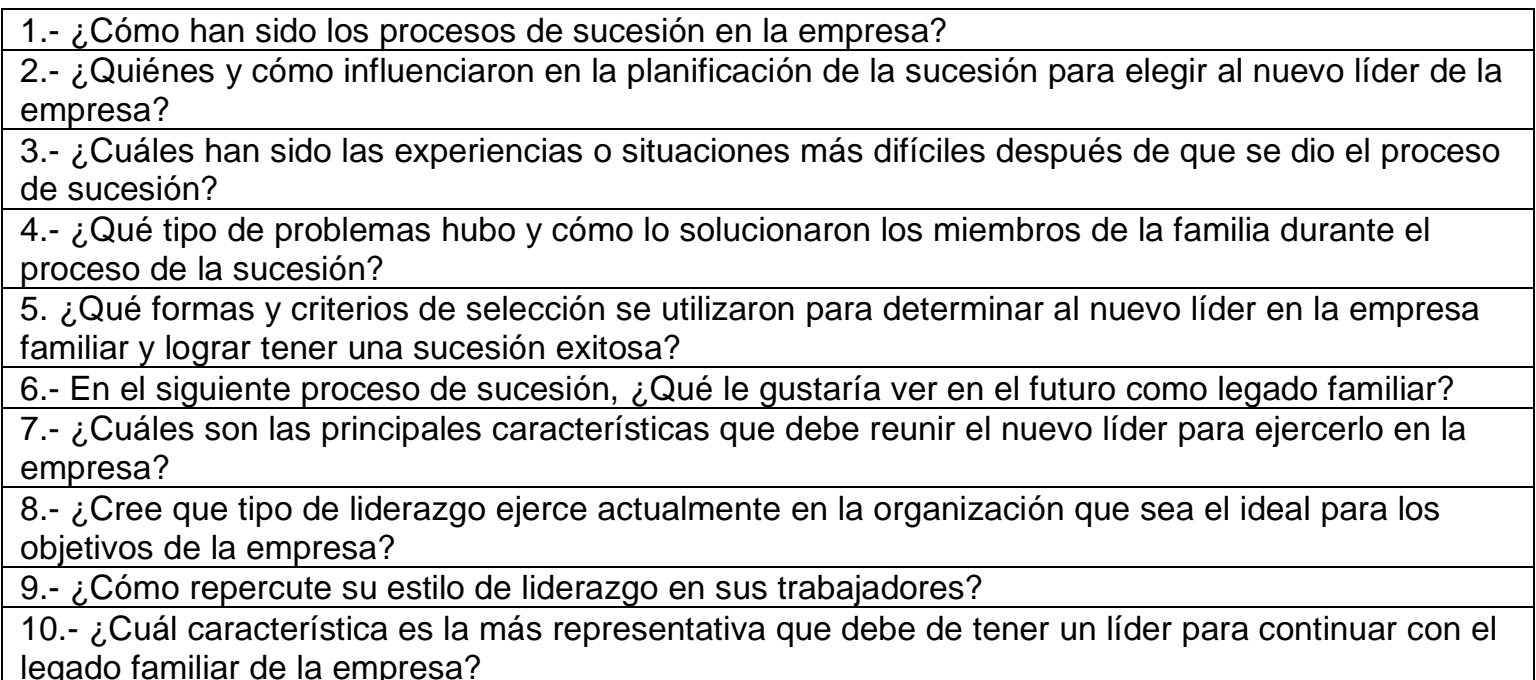

Fuente: Elaboración Propia, en base a Rodriguez y Camacho (2010) y Manning (2013)

La anterior guía fue la base para realizar las entrevistas en la empresa de servicios localizada en el norte de México, conformada primordialmente por el núcleo familiar. Ella cuenta con 16 trabajadores en total, de los cuales, tres de ellos están en atención y colaboración para la alimentación de los trabajadores (comedor y limpieza del mismo), tres son horneadores, uno de ellos amasador, dos están en atención a los clientes (ventas) y el resto está en la producción (elaboración y empaque del producto). Se realizaron ocho entrevistas con representatividad de todos los puestos de la empresa.

Una vez concluidas todas las entrevistas con los informantes de la empresa, se procedió a transcribir cada una de ellas en Word, de las grabaciones electrónicas de audio previamente realizadas, y después procesadas mediante el programa llamado Atlas.ti para integrar datos cualitativos. Se elaboró un documento en Excel en el cual se analizaron todas las palabras repetidas en las entrevistas, y se identificó la relación que guardan entre ellas, para posteriormente agruparlas y determinar las de mayor frecuencia.

Para finalizar, se procedió a realizar un agrupamiento de palabras con el análisis anteriormente realizado, resultando cinco dimensiones: liderazgo, sucesión, familia, valores y empresa. Para concluir, se interpretó cada dimensión y se explicó la relación que tienen dichas dimensiones con las variables de estudio y con la empresa en cuestión.

\section{El estudio de caso}

La empresa en cuestión tuvo sus inicios hace más de 30 años, aproximadamente en 1985, sin embargo, antes de establecer un negocio como tal, su fundadora se dedicaba con anterioridad

\footnotetext{
“Visión de Futuro” Año 16, Volumen N²3 N², Julio - Diciembre 2019 - Pág. 73 - 89

URL de la Revista: http://visiondefuturo.fce.unam.edu.ar/index.php/visiondefuturo/index

URL del Documento: http://visiondefuturo.fce.unam.edu.ar/index.php/visiondefuturo/issue/view/16

ISSN 1668 - 8708 - Versión en Línea 
a la elaboración de galletas y empanadas dulces en su casa, con el apoyo de su familia y algunos vecinos; fue hasta 2006 la apertura de un negocio formal, con productos (empanadas) de diferentes sabores.

La fundadora proviene de una familia trabajadora, tenía 12 hermanos y todos sabían que a ella le interesaba la cocina, al principio elaboraba empanadas de calabaza, pero después empezó a elaborar más mermeladas con la ayuda de sus hijos como dulce de leche, higo y cajeta de guayaba; sus recetas surgieron de estar preparando varios postres y de hacer modificaciones en la masa. Sus hijos y sobrinos eran quienes ayudaban a vender el producto por las calles del poblado, pues su familia siempre apoyaba con el negocio, aunque ellos tenían otras aspiraciones.

Al pasar el tiempo, se formalizó el negocio ante la autoridad hacendaria con la ayuda de una contadora, entonces, la carga de trabajo aumentó, fue allí cuando necesitó la ayuda de alguien más que le ayudara con el negocio, además porque su salud se estaba deteriorando. En ese momento la fundadora decidió llamar a su hijo mayor (actual dueño), para que él fuese quien estuviera en la dirección del negocio. Su hijo vivía en una ciudad cercana con su esposa e hijas. Con el paso del tiempo su hijo era quien se hacía cargo de las compras y llevaba un control en la administración del negocio, mientras que su mamá (fundadora) solamente supervisaba la producción; para ese entonces la fundadora había adquirido un terreno en el cual pidió que las escrituras fueran puestas a nombre de su hijo mayor quien pagaría una parte del costo total de dicho terreno; fue allí donde se construyó un nuevo local, que tardó siete años en edificarse gracias a su actual dueño.

La fundadora se mostraba orgullosa de lo que su hijo había logrado en el tiempo que estuvo ayudándola, tenía certeza que había tomado una buena decisión, ella quería que la tradición, permaneciera como un legado por muchos años, y eso es lo que su hijo ha concretado. Con la ayuda de su familia ha podido sacar adelante el negocio que con tanto esfuerzo ha conseguido, a pesar de las dificultades, ha logrado salir adelante.

Hoy en día, la empresa es ampliamente reconocida no solo en la parte norte de México, sino también en Estados Unidos y varias partes del mundo, turistas han acudido de visita solamente para probar las empanadas en sus diferentes sabores. Al llegar al negocio se puede visualizar parte de la identidad que guarda la familia, como los adornos de carrizo hechos por el mismo dueño, el lema del poblado en la entrada del lugar y sobre todo una fotografía que mantiene viva la imagen de su fundadora, para recordar que ella sigue presente de forma simbólica con el legado gastronómico que se puede disfrutar.

\footnotetext{
“Visión de Futuro" Año 16, Volumen N² 23 N², Julio - Diciembre 2019 - Pág. 73 - 89

URL de la Revista: http://visiondefuturo.fce.unam.edu.ar/index.php/visiondefuturo/index

URL del Documento: http://visiondefuturo.fce.unam.edu.ar/index.php/visiondefuturo/issue/view/16

ISSN 1668 - 8708 - Versión en Línea

E-mail: revistacientifica@fce.unam.edu.ar
} 


\section{Resultados en relación a las variables de estudio}

Previo al proceso de sucesión, la estructura familiar de la empresa, era como el que se puede apreciar en la Fig. №1, conformada por la f undadora y su familia, donde ella como líder y dueña es quien tomaba todas y cada una de las decisiones del negocio familiar.

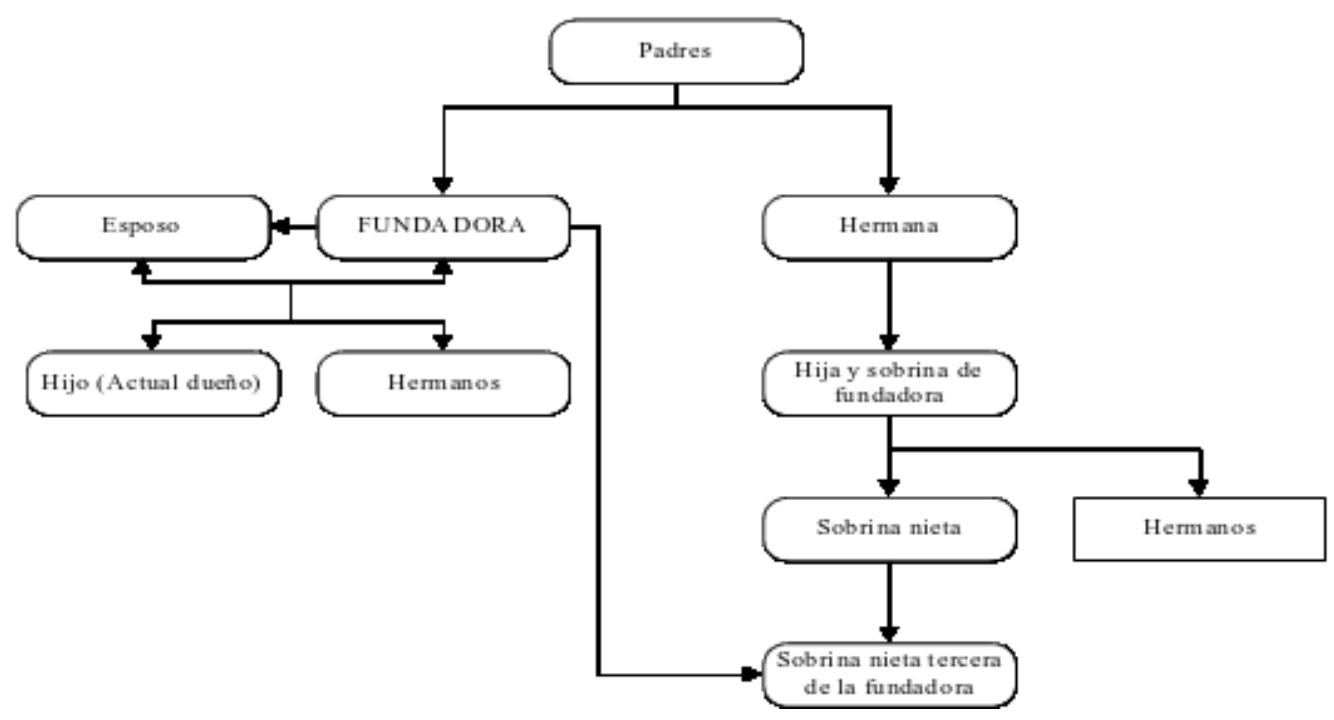

Figura $\mathrm{N}^{\circ}$ 1. Contribución familiar con la fundadora en la empresa

Fuente: Elaboración Propia

Después del proceso de sucesión, la empresa cambió, la conformación de la familia también, así como el organigrama de la misma, ya que existieron algunos problemas familiares. A partir de dicho proceso, una hermana del actual dueño, creó su propia empresa de empanadas gracias a todo lo que aprendió con su mamá; hoy en día tiene sus propios trabajadores.

Dentro de la nueva estructura jerárquica de la empresa, el sucesor es quien dirige, pues para la fundadora era la mejor opción por ser el mejor preparado de la familia para hacerse cargo del negocio. No obstante, al existir ciertas diferencias, la hermana es quien trabaja por su propia cuenta en su empresa, tal como se muestra en la Fig. №2. 


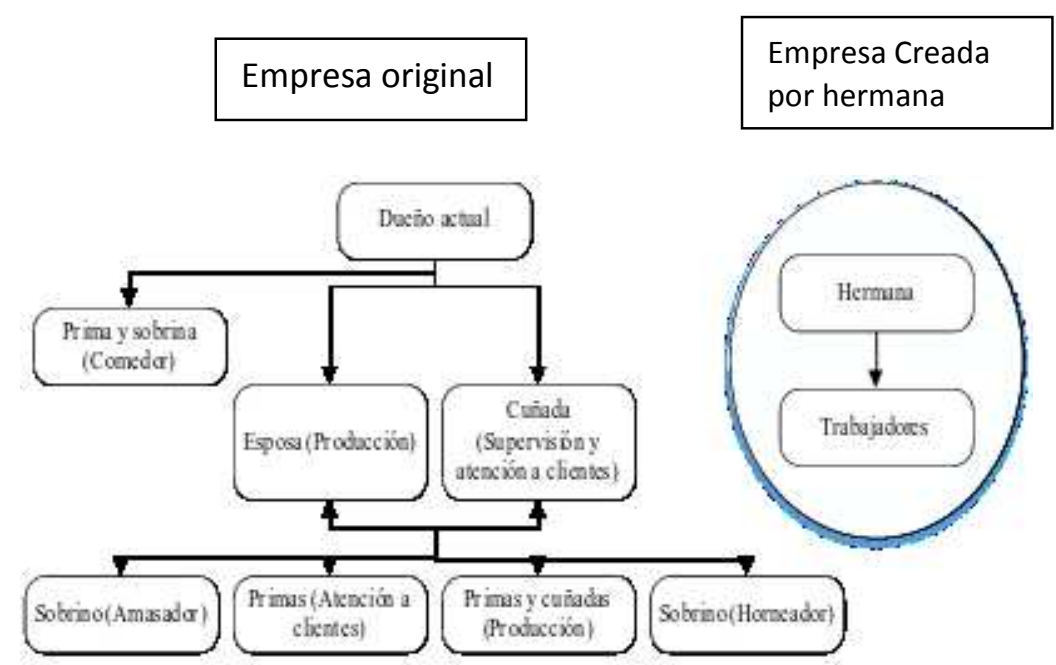

Figura $\mathrm{N}^{\circ}$ 2. Contribución familiar con el dueño act ual en la empresa

Fuente: Elaboración Propia

De las dimensiones estudiadas en la investigación tomando como eje conductor el proceso sucesorio, se analiza cada una de ellas en cuestión temporal antes y después de dicho proceso, tal como se muestra en la Tabla $\mathrm{N}^{\circ} 2$.

Tabla $N^{\circ}$ 2. Empresa antes y después del proceso de sucesión

\begin{tabular}{|c|c|c|}
\hline \multirow[b]{2}{*}{ Dimensión } & \multicolumn{2}{|c|}{ Empresa } \\
\hline & Antes de sucesión & Después de sucesión \\
\hline Familia & $\begin{array}{l}\text { La fundadora, madre del dueño actual, } \\
\text { era la persona de mayor apoyo para la } \\
\text { familia y era quien tomaba las decisiones } \\
\text { de la empresa. Antes de la sucesión solo } \\
\text { se respetaba su opinión ya que era ella } \\
\text { la única quien podía tomar decisiones. }\end{array}$ & $\begin{array}{l}\text { Antes de fallecer la fundadora dejó el } \\
\text { negocio en manos de su hijo mayor. } \\
\text { Varios informantes mencionan que, la } \\
\text { decisión que se tomó fue la mejor. }\end{array}$ \\
\hline Liderazgo & $\begin{array}{l}\text { Desde sus inicios en la empresa solo se } \\
\text { utilizaba un tipo de liderazgo, el cual era } \\
\text { el autocrático y los familiares tenían que } \\
\text { respetar las decisiones que se tomaran. }\end{array}$ & $\begin{array}{l}\text { Hoy en día, eso ha cambiado y el } \\
\text { liderazgo ejercido es el situacional, un } \\
\text { tipo de liderazgo caracterizado por ser } \\
\text { cambiante dependiendo de la situación } \\
\text { en la que se encuentre y así poder tomar } \\
\text { la mejor decisión que según el dueño de } \\
\text { la empresa es siempre velando por el } \\
\text { bien, tanto de la empresa como de los } \\
\text { trabajadores. }\end{array}$ \\
\hline Sucesión & $\begin{array}{l}\text { Anteriormente nunca se realizó un plan } \\
\text { sucesor, ya que no se conocía el término } \\
\text { como tal, sin embargo, se conocía quien }\end{array}$ & $\begin{array}{l}\text { La empresa ha crecido y ha logrado ser } \\
\text { muy competente dentro del mercado } \\
\text { donde se encuentra, y muchos saben } \\
\text { que es una EF exitosa. Sin visualizar }\end{array}$ \\
\hline
\end{tabular}

"Visión de Futuro" Año 16, Volumen No 23 N², Julio - Diciembre 2019 - Pág. 73 - 89

URL de la Revista: http://visiondefuturo.fce.unam.edu.ar/index.php/visiondefuturo/index

URL del Documento: http://visiondefuturo.fce.unam.edu.ar/index.php/visiondefuturo/issue/view/16

ISSN 1668 - 8708 - Versión en Línea 


\begin{tabular}{|c|c|c|}
\hline & $\begin{array}{l}\text { sería el sucesor a cargo de la empresa } \\
\text { para la segunda generación. }\end{array}$ & $\begin{array}{l}\text { aun el futuro de la sucesión para la } \\
\text { tercera generación. }\end{array}$ \\
\hline Valores & $\begin{array}{l}\text { En cualquier empresa es importante } \\
\text { contar con cualidades que hacen ser } \\
\text { única a la empresa, como los valores que } \\
\text { rigen a la misma y por lo que ésta se } \\
\text { caracteriza, como la manera de trabajar } \\
\text { o de convivir dentro y fuera de la } \\
\text { empresa, donde algunos entrevistados } \\
\text { mencionaron que siempre se han } \\
\text { caracterizado por el trabajo en equipo, la } \\
\text { fortaleza y perseverancia. }\end{array}$ & $\begin{array}{l}\text { Con el paso del tiempo y con el éxito que } \\
\text { ha logrado obtener la empresa con su } \\
\text { nuevo dueño, hoy en día se siguen } \\
\text { caracterizando de la misma forma, } \\
\text { destacando que para ellos es importante } \\
\text { seguir de pie y hacer las cosas bien por } \\
\text { lo que tener humildad respetarse y } \\
\text { mantenerse unidos siempre les ha } \\
\text { funcionado. }\end{array}$ \\
\hline $\begin{array}{l}\text { Empresa } \\
\text { (Propiedad) }\end{array}$ & $\begin{array}{l}\text { La empresa no era vista como un } \\
\text { negocio por parte de su fundadora, ya } \\
\text { que lo veía como un desarrollo para } \\
\text { sacar adelante a su familia, su fundadora } \\
\text { hacía lo que le apasionaba. }\end{array}$ & $\begin{array}{l}\text { Con el nuevo dueño, las cosas } \\
\text { empezaron a cambiar y la } \\
\text { administración se volvió más enfocada a } \\
\text { negocio, y hoy en día sigue teniendo } \\
\text { éxito gracias a los productos que la } \\
\text { fundadora dejó, y que su hijo ha logrado } \\
\text { mantener como un legado que } \\
\text { cualquiera puede disfrutar. }\end{array}$ \\
\hline
\end{tabular}

Fuente: Elaboración Propia

\section{CONCLUSIÓN}

La presente investigación tuvo por objetivo identificar el tipo de liderazgo ejercido durante el proceso de sucesión en una empresa familiar mexicana, a través de diversas entrevistas semiestructuradas, lo cual se logró. En ese sentido, los principales hallazgos permiten generar las siguientes conclusiones en tres vertientes. La primera de ellas es que a través del proceso sucesorio se traspasa la dirección del negocio a una nueva persona, sin embargo, el tipo de liderazgo no se genera por herencia, sucesión o tradición. Cada directivo dirigirá a la empresa de acuerdo a sus capacidades, aptitudes y actitudes, de tal forma que la fundadora lo hacía de manera autócrata y el sucesor con cierta flexibilidad dependiendo de la situación.

Posterior al proceso de sucesión, el nuevo dirigente de mayor jerarquía genera una reconfiguración en la estructura organizacional, por una parte, al establecer una nueva relación entre los miembros de la empresa y de la familia, por la otra, al incorporar al negocio a familiares con mayor cercanía generacional y del núcleo.

Con amplia relación con lo anterior, la decisión del nuevo sucesor no es aceptada por todos, ello origina conflictos familiares, manifestado en la inconformidad de uno de los posibles sucesores, generando la separación y el disgusto entre ellos, lo cual deriva en la apertura de una nueva empresa competidora.

\footnotetext{
"Visión de Futuro" Año 16, Volumen N² 23 N², Julio - Diciembre 2019 - Pág. 73 - 89

URL de la Revista: http://visiondefuturo.fce.unam.edu.ar/index.php/visiondefuturo/index

URL del Documento: http://visiondefuturo.fce.unam.edu.ar/index.php/visiondefuturo/issue/view/16

ISSN 1668 - 8708 - Versión en Línea 
Así pues, se debe profundizar en los aspectos posteriores a la decisión y el ejercicio del liderazgo en relación con el desempeño de la empresa, la estructura de la organización y familiar, así como disminuir y evitar los conflictos que tengan consecuencias de separación empresarial y/o familiar. Uno de los objetivos de este tipo de empresas es que sea precisamente la familia la que permanezca como dueña en las siguientes generaciones, aportando beneficios tanto para la familia como para la sociedad en general, favoreciendo así a su continuidad y permanencia.

\section{REFERENCIAS}

Andrade, J. (2002). Sucesión en la empresa familiar: su futuro cuando la muerte se acerca. Revista Venezolana de Gerencia (RVG). 7(19), 375-389. Recuperado de https://www.redalyc.org/html/290/29001903/

Araya, A. (2012). El proceso de sucesión en la empresa familiar y su impacto en la organización. Tec Empresarial. 6(2), 29-39. Recuperado de http://revistas.tec.ac.cr/index.php/tec empresarial/article/view/527.

Arenas, H., \& Rico, D. (2014). La empresa familiar, el protocolo y la sucesión familiar. Estudios Gerenciales. 30(132), 252-258. Recuperado de https://www.icesi.edu.co/revistas/index.php/estudios gerenciales/article/view/1812.

Arteaga, A., \& Soraya, R. (2009). Liderazgo resonante según Género. Multiciencias. 9(3), 289295.

Recuperado de

http://www.produccioncientifica.luz.edu.ve/index.php/multiciencias/article/view/16790.

Ávila, H. (2006). Introducción a la metodología de la investigación, (1ed.), España, EUMED. Recuperado

https://books.google.com.mx/books?id=r93TK4EykfUC\&printsec=frontcover\&hl=es\#v=one page \&q\&f=false.

Bastar, S. (2006). El liderazgo en las pequeñas empresas mexicanas de propiedad familiar. Iztapalapa, México. Recuperado de http://148.206.53.84/tesiuami/UAMI13126.pdf.

Blake, R., \& Mouton, J. (1980). El nuevo Grid gerencial. (1 ed.) México, Diana. Recuperado de: http://biblioteca.utec.edu.sv/siab/virtual/auprides/29989/capitulo\%201.pdf.

Carrión, N. (2017). Modelo de liderazgo basado en el coaching para el directivo de una empresa hotelera en la ciudad de Piura. Facultad de Ciencias Económicas y Empresariales, 14(2), 369-387. Recuperado de https://pirhua.udep.edu.pe/handle/11042/2869.

\footnotetext{
“Visión de Futuro" Año 16, Volumen N² 23 N², Julio - Diciembre 2019 - Pág. 73 - 89

URL de la Revista: http://visiondefuturo.fce.unam.edu.ar/index.php/visiondefuturo/index

URL del Documento: http://visiondefuturo.fce.unam.edu.ar/index.php/visiondefuturo/issue/view/16

ISSN 1668 - 8708 - Versión en Línea

E-mail: revistacientifica@fce.unam.edu.ar
} 
Cazau, P. (2006). Introducción a la investigación en ciencias sociales, (3 ed.) Argentina, Fondo de Cultura Económico. Recuperado de https://educacionparatodalavida.files.wordpress.com/2015/10/cazau pablo introduccion a la investigacion.pdf

Figueroa, M. (2012). Principales modelos de liderazgo: su significación en el ámbito Universitario. Humanidades MéDicas, 12(3), 515-530. Recuperado de http://www.humanidadesmedicas.sld.cu/index.php/hm/article/view/252/167

Gil, F., Alcover, M., Rico, R., \& Sánchez, M. (2011). Nuevas formas de liderazgo en trabajo de equipo. Papeles del Psicólogo, 32(1), 38-47. Recuperado de https://www.redalyc.org/pdf/778/77817210005.pdf.

Goleman, D. (2013). Liderazgo. El poder de la inteligencia emocional. B Grupo Z, 83-162. Recuperado de http://blogs.fad.unam.mx/asignatura/claudia mena/wpcontent/uploads/2015/08/IntEmoc.pdf.

González, F., \& Navas, W. (2017). Principales factores que afectan el proceso de sucesión en las empresas familiares. ResearchGate, 2(4), 45-56. Recuperado de file://C:/Users/hp/Downloads/46-323-1-PB.pdf.

Gonzalo, Z. (2006). El liderazgo y la empresa familiar. Buenos Aires, Argentina. Vaneduc.edu.ar Recuperado de http://imgbiblio.vaneduc.edu.ar/fulltext/files/TC069868.pdf.

Jiménez, M., \& Piña, H. (2006). Capital social en las empresas familiares. Revista Venezolana de Gerencia (RVG), 16(54), 255-273. Recuperado de https://www.redalyc.org/html/290/29018865005/.

Lee, C. (2012). Familia, comunidad generadora de conocimientos en las empresas familiares. Multiciencias, 12(1), 115-120. Recuperado de https://www.researchgate.net/publication/301201676 Familia comunidad generadora de conocimientos en las empresas familiares.

Lozano, M., \& Urbano, D. (2017). Relevant factors in the process of socialization, involvement and belonging of descendants in family businesses. Innovar, 27(63), 61-76. Recuperado de http://www.scielo.org.co/scielo.php?script=sci arttext\&pid=S0121-50512017000100061.

Manning, L. (2013). Leadership and succession planning in a family organization. ProQuest, 17(1), 1-143. Recuperado de https://scholar.google.com.mx/scholar?hl=es\&as sdt=0\%2C5\&q=Leadership+and+succes $\underline{\text { sion+planning }+i n+a+f a m i l y+o r g a n i z a t i o n \& b t n} G=$.

Manzano, G., \& Ayala, J. (2002). Sucesión en la empresa familiar: algunas claves de éxito. Boletín de Estudios Económicos, 57(177), 433-449. Recuperado de 
https://www.researchgate.net/publication/298789580 Sucesion en la empresa familiar algunas claves del exito.

Mariscal, D., Silva, I., \& Contreras, I. (2016). Empresas familiares y factores que influyen en el éxito del proceso de sucesión desde la perspectiva del sucesor potencial. Unidad académica de contaduría y administración, 311(122,) 85-51. Recuperado de http://www.fca.uach.mx/apcam/2016/02/02/PONENCIA 101 UAN Tepic.pdf.

Ochoa, S. Jacobo C. Y Leyva, B. (2015). Estudio de la Pyme familiar, una visión multivarble, (1 ed.) México, Pearson Educación. Recuperado de https://www.researchgate.net/publication/322287592 Estudio de la Pyme familiar Una vision multivariable.

Pantoja, M., Moncayo, R., Belalcázar, A., \& Jiménez, A. (2016). La sucesión en empresa familiar: una aproximación al estado de arte. Revista UNIMAR, 34(1), 219-229. Recuperado de file://C:/Users/hp/Downloads/1146-Texto\%20del\%20art\%C3\%ADculo-2540-1-1020170123.pdf.

Quijada, R., \& Ávila, J. (2016). Empresas familiares: conceptos, teorías y estructuras. Revista Escuela de Administración de Negocios, 149-157. Recuperado de http://www.scielo.org.co/pdf/ean/n81/n81a08.pdf.

Rendón, M. (9 y 10 de diciembre de 2010). El estudio de la pequeña empresa familiar en México: una perspectiva analítica. VI Jornadas de Sociología de la UNLP. Universidad Nacional de La Plata, Argentina. Recuperado de http://www.memoria.fahce.unlp.edu.ar/trab eventos/ev.5336/ev.5336.pdf.

Rodríguez, M., \& Camacho, J. (2010). El quehacer productivo y la sucesión de liderazgo de una empresa familiar. Sinaloa, México. Recuperado de http://acacia.org.mx/busqueda/pdf/03 PF150 El Quehacer Productivo.pdf.

Salazar, G. (2014). Empresas Familiares. Recuperado de http://www.biblioferrersalat.com/media/documentos/Curso\%20Introductorio\%20EF\%20Gui \|lermo\%20Salazar.PDF.

Saldaña, Y., Ruiz, F., \& Gaona, L. (2016). El liderazgo a partir del proceso de la sucesión en la empresa familiar mexicana. Revista Global de Negocios, 4(6), 1-20. Recuperado de http://www.theibfr2.com/RePEc/ibf/rgnego/rgn-v4n6-2016/RGN-V4N6-2016-5.pdf.

Sánchez, E. (2000). Teoría del liderazgo situacional en la administración local, Psicothema, 12(3), 435-439. Recuperado de http://www.psicothema.com/pdf/353.pdf. 
Sandoval, J., \& Guerrero, D. (2010). Empresas Familiares en Colombia, hacia la construcción de un modelo de gestión comercial. Revista U.D.C.A Actualidad \& Divulgación Científica, 3(1): 135-146. Recuperado de https://revistas.udca.edu.co/index.php/ruadc/article/view/717.

San Martin, J., \& Durán, J. (2016). Sucesión y su relación con endeudamiento y desempeño en empresas familiares. Contaduría y Administración,61(1), 41-57. Recuperado de http://www.cya.unam.mx/index.php/cya/article/viewFile/785/892.

Santamaría, E., \& Pico, F. (2015). Sucesión en las empresas familiares: análisis de los factores estratégicos que influyen en la dinámica familia-empresa. Revista Politécnica, 35(2), 1-11. Recuperado

de https://www.revistapolitecnica.epn.edu.ec/ojs2/index.php/revista politecnica2/article/view/ $\underline{383}$.

Soto, B. (2012). Tipos de Liderazgo, España. Gestión.org. Recuperado de https://www.gestion.org/recursos-humanos/liderazgo/29890/tipos-de-liderazgo/.

Tagiuri, R., \& Davis, J. (2012). El modelo de la empresa familiar: Los cuatro pilares fundamentales. Revista de Investigación: Área de Innovación y Desarrollo, Ciencias. Recuperado de file://C:/Users/hp/Downloads/Dialnet-EIModeloDeEmpresaFamiliar4817932.pdf.

Tapiés, J. (2010). Sucesión en la empresa familiar. México.Deloitte.com. Recuperado de https://www2.deloitte.com/content/dam/Deloitte/mx/Documents/risk/GobiernoCorporativo/sucesion-empresa-familiar.pdf.

Ulloa, J., Nail, O., Castro, A., \& Muñiz, M. (2012). Problemas de gestión asociados al liderazgo como función directiva. Estudios Pedagógicos, 38(1), 121-129. Recuperado de https://scielo.conicyt.cl/scielo.php?script=sci arttext\&pid=S0718-07052012000100007.

Vallejo, M. (2007). El compromiso en la empresa familiar bajo una óptica de liderazgo transformacional y aprendizaje organizacional. Investigaciones europeas de dirección y economía de la empresa, 13(3), 217-234. Recuperado de file:///C:/Users/hp/Downloads/Dialnet-

EICompromisoEnLaEmpresaFamiliarBajoUnaOpticaDeLide-2527019.pdf.

Vallejo, M. (2009). Liderazgo transformacional y sus efectos en las empresas familiares: un análisis diferencial. Revista Europea de Dirección y Economía de la Empresa, 18(1), 105122. Recuperado de https://dialnet.unirioja.es/servlet/articulo?codigo=2878067.

Van, D. \& Yukl, G. (2015), Theory and research on leadership in organizations, Consulting Psychologists, 3(1) 145-197. Recuperado de https://psycnet.apa.org/record/1993-97201$\underline{003}$

\footnotetext{
“Visión de Futuro" Año 16, Volumen N²3 N², Julio - Diciembre 2019 - Pág. 73 - 89

URL de la Revista: http://visiondefuturo.fce.unam.edu.ar/index.php/visiondefuturo/index

URL del Documento: http://visiondefuturo.fce.unam.edu.ar/index.php/visiondefuturo/issue/view/16

ISSN 1668 - 8708 - Versión en Línea

E-mail: revistacientifica@fce.unam.edu.ar
} 
Velázquez, M., Paz, C., \& Aguilar, N. (2011). La sucesión en una empresa familiar de autotransporte. Hitos de ciencias económico administrativas, 17(48), 65-74. Recuperado de http://revistas.ujat.mx/index.php/hitos/article/view/468/0.

Virick, M., \& Greer, C. (2012). Gender diversity in leadership succession: preparing for the future. Human Resource Management, 54(4), 575-600. Recuperado de https://onlinelibrary.wiley.com/doi/abs/10.1002/hrm.21487.

Zarate, R., \& Matviuk, S. (2012). Inteligencia emocional y prácticas de liderazgo en las organizaciones colombianas. Colciencias, 28(47), 91-104. Recuperado de http://www.scielo.org.co/pdf/cuadm/v28n47/v28n47a08.pdf.

\section{RESUMEN BIOGRAFICO}

\section{Lic. María Olivia Palafox Soto}

Es licenciada en Administración de Empresas Turísticas por parte del Instituto Tecnológico de Sonora, México; actualmente estudia la Maestría en Gestión Organizacional en la misma institución, la cual pertenece al Programa Nacional de Posgrados de Calidad (CONACyT). Intereses de investigación: cultura organizacional, liderazgo y empresas familiares.

\section{Dr. Sergio Ochoa Jiménez (Autor Correspondencia)}

Doctor en Estudios Organizacionales por parte de la UAM-Iztapalapa; México. Responsable del Cuerpo Académico Consolidado de Estudio de las Organizaciones y Jefe del Departamento de Ciencias Administrativas en el Instituto Tecnológico de Sonora. Línea temática de investigación: Gestión del conocimiento e innovación, Cultura Organizacional y Empresa Familiar.

\section{Dr. Carlos Armando Jacobo Hernández}

Es doctor en planeación estratégica para la mejora del desempeño por el Instituto Tecnológico de Sonora. Es miembro del cuerpo académico "estudios organizacionales" y actualmente coordina la Maestría en Gestión Organizacional en el Instituto Tecnológico de Sonora, la cual pertenece al Programa Nacional de Posgrados de Calidad (CONACyT).

\footnotetext{
"Visión de Futuro" Año 16, Volumen No 23 N², Julio - Diciembre 2019 - Pág. 73 - 89

URL de la Revista: http://visiondefuturo.fce.unam.edu.ar/index.php/visiondefuturo/index

URL del Documento: http://visiondefuturo.fce.unam.edu.ar/index.php/visiondefuturo/issue/view/16

ISSN 1668 - 8708 - Versión en Línea 